Review

\title{
Endoscopy to Diagnose and Prevent Digestive Cancers in Lynch Syndrome
}

\author{
Raphael Olivier ${ }^{1, *}$, Violaine Randrian ${ }^{1}$, David Tougeron ${ }^{1}$ and Jean-Christophe Saurin ${ }^{2}$ \\ 1 Gastroenterology Department, Poitiers University Hospital (CHU de Poitiers), 86000 Poitiers, France; \\ violaine.randrian@chu-poitiers.fr (V.R.); david.tougeron@chu-poitiers.fr (D.T.) \\ 2 Gastroenterology Department, Hospices Civils de Lyon-Centre Hospitalier Universitaire, \\ 69002 Lyon, France; jean-christophe.saurin@chu-lyon.fr \\ * Correspondence: raphael.olivier@chu-poitiers.fr; Tel.: +33-05-49-44-37-51; Fax: +33-05-49-44-38-35
}

Citation: Olivier, R.; Randrian, V.;

Tougeron, D.; Saurin, J-C.

Endoscopy to Diagnose and Prevent

Digestive Cancers in Lynch

Syndrome. Cancers 2021, 13, 3505.

https://doi.org/10.3390/

cancers13143505

Academic Editor: Fiona M. Lyng

Received: 4 April 2021

Accepted: 9 July 2021

Published: 13 July 2021

Publisher's Note: MDPI stays neutral with regard to jurisdictional claims in published maps and institutional affiliations.

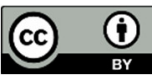

Copyright: (C) 2021 by the authors. Licensee MDPI, Basel, Switzerland. This article is an open access article distributed under the terms and conditions of the Creative Commons Attribution (CC BY) license (http://creativecommons.org/licenses /by/4.0/).
Simple Summary: Lynch syndrome is characterized by a higher relative risk of developing certain cancers, especially digestive cancers. Many guidelines from different scientific societies are now available and allow excellent follow-up for these patients, but occasionally propose divergent management approaches. We provide here a synthesis of these guidelines and $\mathrm{z}$ focus on prevention, diagnosis, and endoscopic follow-up of these digestive cancers and early neoplasia.

\begin{abstract}
Lynch syndrome patients could benefit from various recommendations to prevent digestive cancers. In this review, we summarize the criteria to identify Lynch syndrome in patients with digestive cancers. We detail endoscopic screening procedures in patients with Lynch syndrome for gastric, small bowel, pancreatic, and colorectal cancers. We review the precise modalities of endoscopic follow-up, particularly the discrepancies that exist between the guidelines of the various scientific societies. We discuss the treatment of colorectal cancers in Lynch syndrome cases and patient adherence to endoscopic follow-up programs.
\end{abstract}

Keywords: Lynch syndrome; digestive endoscopy; colorectal cancer

\section{Introduction}

The large majority of colorectal cancers (CRCs) are sporadic. Nevertheless, different studies have indicated that $35 \%$ of CRC cases have a familial component [1], and in $2-5 \%$ of CRC cases, a genetic origin can be identified [2]. Lynch syndrome (LS) is the most common hereditary colorectal cancer syndrome, with an estimated population frequency of $1 / 280$ individuals [3,4]. LS represents about 3\% of all CRCs [5]. It is linked to a germline mutation in one of the DNA mismatch repair (MMR) system genes (MLH1, MSH2, MSH6, or PMS2 or a deletion in the $3^{\prime}$ region of the epithelial cell adhesion molecule (EPCAM) gene 4) [2]. The inactivation of the MMR system leads to errors during the replication of repeated DNA sequences, called microsatellites, resulting in microsatellite instability (MSI).

Determination of MMR deficiency (dMMR) and MSI status has a major impact on CRC management, notably in Lynch syndrome follow-up, and has major prognostic and predictive value [5]. MMR deficiency/MSI status is associated with a better prognosis in patients with non-metastatic CRC; that said, stage II dMMR/MSI CRCs show chemoresistance to adjuvant 5-fluorouracil alone [6,7]. By contrast, these patients are sensitive to adjuvant oxaliplatine-based chemotherapy [8]. At a metastatic stage, however, $\mathrm{dMMR} / \mathrm{MSI}$ CRCs are associated with very poor survival and chemoresistance [9]. Nevertheless, dMMR/MSIs at both non-metastatic and metastatic stages are very sensitive to immune checkpoint inhibitors [10]. In other digestive tumors, primarily gastric and small bowel adenocarcinoma, MSI status has been associated with good prognosis and high 
sensitivity to immune checkpoint inhibitors [11]. Finally, in LS families, endoscopic follow-up is a major issue in efforts to remove pre-cancerous lesions, prevent cancer, and allow early detection of neoplasia.

In this review, we propose to clarify the clinical criteria identifying Lynch syndrome in patients with digestive cancers. We will then summarize the recommended endoscopic follow-up in this syndrome. While many guidelines are now available, discrepancies may appear, confusing the clinician. We thus propose a synthesis of the recommendations, with the objective being to determine the most efficient and consensual management of the patient.

\section{Criteria to Identify and Diagnose Lynch Syndrome}

\subsection{Clinical Suspicion of Lynch Syndrome}

It should be recalled that LS is characterized by a higher relative risk of developing specific cancers. The most common ones include CRC, endometrial, small intestine, and urothelial carcinoma (involving the upper urinary tract); rarer cancers are also possible: ovarian cancers, glioblastomas, sebaceous skin tumors, cholangiocarcinomas, and gastric adenocarcinomas. LS should be suspected if a patient presents one or several cancers from these spectrums, especially at a young age. We will focus in this review on digestive cancers, owing to their screening eligibility, especially colorectal cancer.

Some clinical criteria may help to identify LS. The Bethesda criteria revised in 2004 are probably the most useful thanks to their simplicity of use and their precise description (Table 1) [12]. In contrast, the Amsterdam II criteria are clearly too restrictive with a high rate of false negatives [13], despite their specificity. Too many patients were not diagnosed because they did not necessarily meet the four criteria. In clinical practice, colorectal cancer patients with family history meeting either the Amsterdam II criteria and/or the revised Bethesda criteria should receive systematic MSI testing and/or IHC for MMR protein expression and probably be referred for oncogenetic consultation.

The European recommendations encourage tumor screening for MSI and/or loss of expression of MMR proteins in immunohistochemistry (IHC) for any patient under 70 years of age presenting a first CRC [14] without taking into consideration the spectrum of the other cancers. The recommendations vary from country to country; for example, in the American [15,16] and British recommendations [17], the search for MSI and/or loss of MMR protein expression in IHC is recommended for all initially diagnosed CRCs (Table 2). In the case of high suspicion of LS, i.e., using revised Bethesda criteria, CRC patients must have MMR IHC/MSI tests. Nevertheless, because of the major therapeutic impact of dMMR/MSI status, universal screening of all CRCs can be proposed.

Table 1. Amsterdam II and Bethesda revised criteria.

\section{Amsterdam II Criteria}

\section{Patients with the following four criteria:}

At least three subjects with HNPCC narrow spectrum, one of whom is related to the other two in the first degree

At least one cancer diagnosed before the age of 50

At least two successive generations concerned

Exclusion of familial polyposis

\section{Revised Bethesda Criteria}

Patient with CRC diagnosed before age 50

Patient with CRC with microsatellite instability and/or loss of MMR protein expression in IHC before the age of 60 years

Patient with two synchronous or metachronous cancers belonging to the HNPCC broad spectrum regardless of age

Patient with a CRC and two or more first- or second-degree relatives with HNPCC broad-spectrum regardless of age Patient with CRC and a first-degree relative with broad-spectrum HNPCC diagnosed before age 50

CRC: colorectal cancer; HNPCC: hereditary non-polyposis colorectal cancer; IHC: immunohistochemistry; MMR: mismatch repair system. 
Table 2. Indications for immunohistochemistry (IHC) and/or microsatellite instability (MSI) testing.

\begin{tabular}{c}
\hline American and British Guidelines [8-10] \\
\hline Any patient with new colorectal cancer diagnosed \\
European Guidelines [18] \\
\hline Any patient under 70 years of age presenting a first CRC \\
\hline
\end{tabular}

\subsection{Somatic Analyses of Colorectal Lesions in the Case of Suspected Lynch Syndrome}

In the case of suspicion of LS, it is first required to confirm MSI and loss of expression of MMR proteins by IHC. These somatic tests are performed on the tumor, and dMMR phenotype is defined by nuclear loss of expression of one or more MMR proteins. As they function as dimers, mutation generally concerns two proteins, even if only one is mutated (MLH1/PMS2 or MSH2/MSH6). This method also suggests the mutated gene corresponding to the lost proteins [18]. MSI phenotype is determined by polymerase chain reaction using a panel of five microsatellite mononucleotide markers, called Pentaplex (BAT-25, BAT-26, NR-21, NR-22, and NR-24 or BAT-25, BAT-26, D5S346, D2S123, and D17S250) $[19,20]$. Instability of at least three markers defines MSI status. dMMR/MSI CRCs with no MLH1 promoter hypermethylation and/or BRAF mutation should have genetic counseling MMR germline testing to confirm LS. Lynch-like syndrome (LLS) has been proposed for patients with a family history of cancers associated with Lynch syndrome, but no pathogenic germline MMR mutation [21]. According to family history and oncogenetician recommendations, these patients should undergo endoscopic screening.

Both methods could be used, but some studies have shown discordances between MMR protein IHC and MSI molecular testing, with rates ranging from $1 \%$ to $10 \%$ [22-24]. Expert centers usually perform both tests. That said, these tests are expensive, with limited availability, and time- consuming. It is consequently recommended to use only one test as universal screening of all CRC patients with no suspicion of LS [25]. By contrast, two tests should be performed in the event of high suspicion of LS (e.g., multiple LS cancer spectrums in the family) $[18,26]$. The major impact in the case of proven LS justifies the propensity to perform both tests in order not to avoid missing out on LS.

It is worth noting that, whenever possible, these tests should be performed on cancers and not on adenomas, as false negative results exist [27]. Indeed, the combination of MSI and IHC testing in colorectal adenomas is useful only when LS is suspected and adenomatous polyps are the only tissues available for analysis. A negative result does not exclude the presence of LS, especially in the case of low-grade dysplasia adenomas.

In conclusion, screening for MSI and/or loss of expression of MMR proteins by IHC for all CRCs represents to an ever greater extent a gold standard and should be widely proposed.

\section{Endoscopic Follow-Up for Patients with Lynch Syndrome}

Gastroenterology societies have published guidelines for high-risk CRC patients screening and follow-up, especially the British Society of Gastroenterology (BSG), the Association of Coloproctology of Great Britain and Ireland (ACPGBI), the United Kingdom Cancer Genetics Group (UKCGG) [17], and the European Society of Gastrointestinal Endoscopy (ESGE) Guidelines [28].

\subsection{Follow-Up in Expert Networks/Centers}

One major point is that patients with LS should be followed in expert centers with specialized networks. The efficacy of colonoscopy follow-up and adenoma resection on the incidence and mortality of CRC in LS patients is well-known [29-31]. As this monitoring is lifelong and difficult from a psychological point of view, patient adherence is essential. Studies have demonstrated the efficacy and benefit of cancer risk education [32] and standardized surveillance programs $[33,34]$ to improve compliance to colonoscopy in 
LS patients. Inclusion in national registries, associated with endoscopic surveillance programs and the use of reminders, results in high compliance rates [25,35-37].

Specialized networks have been developed and permit better follow-up of LS families, especially with respect to the endoscopy timelines. They encourage international, multicenter, prospective, observational studies, using the Prospective Lynch Syndrome Database (PLSD) [38], which allows the pooling of data from several collaborating European centers. "Real-life" data suggest that current management guidelines for Lynch syndrome should be more specific and be revised in light of the different gene- and gender-specific cancer risks.

\subsection{Follow-Up of the Upper Digestive Tract}

Regarding upper digestive tract management, despite a low level of evidence, most recommendations are in favor of the absence of routine surveillance for the small bowel and stomach. These explorations should take place only if the patient is symptomatic or if there is an upper digestive tract lesion in the family.

\subsubsection{Gastric Cancer}

Individuals with LS have an overall lifetime cumulative risk of $0.7-13 \%$ of developing gastric cancer [39]. There is a trend toward higher prevalence of gastric cancer in carriers of $M L H 1$ and $M S H 2$ mutations compared with carriers of $M S H 6$ mutations [39]. Three observational studies provide information about upper gastrointestinal endoscopy monitoring in LS. In the first one, no gastric cancer was diagnosed, but only 32 gastroscopies were performed in 21 patients ( $32 \%$ of the population) during a ten-year follow-up [40]. In the second study, including 443 patients, gastric endoscopy was done in about $30 \%$ of cases; eight gastric cancers were identified and the rate of Helicobacter pylori (HP) infection did not differ from the general population [41]. The last work is a comparative study, where a single upper gastrointestinal endoscopy was proposed in both MLH1 mutation carriers $(n=73)$ and mutation-negative family members $(n=32)$ [42]. The rates of HP infection, intestinal atrophy, and metaplasia were similar in both groups. No gastric neoplastic lesion was detected in either group, and only one case of duodenal cancer was detected in the mutation-positive group [42].

In conclusion, there is no convincing evidence of the usefulness of gastric surveillance in patients with LS. However, it appears mandatory to screen LS patients for HP, with subsequent eradication therapy if present. The HP infection rates seem effectively similar in LS patients and the general population [41,42]. The eradication of HP has reduced the incidence of gastric cancer by $35 \%$ in the general population [43,44]. A major study involving 1632 patients showed that, among persons with HP infection who had a family history of gastric cancer in first-degree relatives, HP eradication treatment also reduces the risk of gastric cancer [45].

Owing to a low gastric cancer risk in published series, routine surveillance does not seem necessary, but Helicobacter pylori screening should be systematically performed in patients with Lynch syndrome.

\subsubsection{Small Bowel Adenocarcinoma}

In LS families, small bowel tumors are located mainly in the duodenum $(43 \%)$ and the jejunum (33\%). The cumulative lifetime risk of developing small bowel adenocarcinoma (SBA) has been estimated at $4.2 \%$ in patients with germline MLH1 and MSH2pathogenic variants [46]. A recent study has reported gene-specific prospective cumulative cancer risks for duodenal adenocarcinoma in 3119 patients with LS. The risk of duodenal carcinoma was reported to be the highest for MLH1 pathogenic variant carriers (6.5\% for $M L H 1$ and $2.0 \%$ for $M S H 2$ carriers). No small bowel cancer was observed in patients with MSH6 or PMS2mutations (462 and 124 patients, respectively, with mean follow-up of about 5 years) [47]. The median age of SBA diagnosis in LS patients ranged 
from 39 to 53 years [48-50]. Adenocarcinoma has been found in a large majority of cases $(81 \%$ to $100 \%)[50,51]$. It has also been suggested that LS-related SBA has a better prognosis than sporadic SBAs [47]. There is no demonstration of an excessive risk of SBA in the case of a first-degree relative with a history of SBA [52].

Two studies have evaluated video-capsule endoscopy (VCE) for small bowel neoplasia screening in LS, with prevalence of $8.6 \%$ of neoplasia (including adenomas and cancers) and $1.5 \%$ of cancers, respectively [53,54]. In most international guidelines, the frequency of cancer has appeared too low to justify systematic VCE screening. False-positive results have been found in at least $11 \%$ of patients, and are responsible for invasive secondary procedures such as balloon-enteroscopy or magnetic resonance enteroclysis [53].

The prospective study showed no SBA after average follow-up of 40 months in 35 patients with VCE screening, and compared the capsule to computed tomographic enteroclysis that missed two out of three cases of small bowel neoplasia [54]. Another retrospective study from the same team confirmed the limited benefit of VCE, detecting no small bowel neoplasia despite its repetition at an average interval of two years in $78 \%$ of the study population [55]. Finally, larger and prospective studies are required before drawing a definitive conclusion.

Interestingly, as most cancers are duodenal (with up to $6.5 \%$ cumulative risk in some mutation carriers), prospective studies evaluating gastroscopy with a longer endoscope (for examination of the proximal small bowel) would also be of interest.

There is currently not enough evidence to recommend routine small bowel monitoring, including by VCE. Larger studies are needed, and could also evaluate upper digestive endoscopy targeting the proximal and distal duodenum.

\subsection{Follow-Up of the Lower Digestive Tract}

3.3.1. Endoscopic Aspect of Sessile Serrated Lesions and Colorectal Polyps in Lynch syndrome

Usual colonic and small bowel adenomas are observed in LS, but it seems that sessile serrated polyps are also quite common in this disease. The role of sessile serrated lesions (SSL) and the serrated neoplasia pathway in LS is not fully understood. In one retrospective study, the frequency of SSL in LS patients was comparable to that of a matched general population group [56]. Non-polypoid adenomas (flat adenomas) are more frequently observed in LS patients than in people at average risk for CRC. SSLs are defined with a height of less than half the diameter, and advanced histology is defined by the presence of high-grade dysplasia or in situ carcinoma. In one study on 59 LS patients, adenomas were significantly more likely to be non-polypoid than they were in the 590 controls $(43.3 \%$ vs. $16.9 \%, p<0.001)$, and were particularly present in the proximal colon [57].

\subsubsection{Colorectal Cancer}

\section{- $\quad$ Age to start screening}

The recommended follow-up begins at 20-25 years old for MLH1 and MSH2 pathogenic variant carriers and 30-35 years old for MSH6 or PMS2 mutation carriers, according to recent recommendations $[17,28]$. It is difficult to clarify, using evidence-based medicine, the appropriate age to start colonoscopic surveillance, even if this can be inferred from the individual risk of developing CRC in view of familial CRC history. However, several studies, even if not randomized, showed that this risk is dependent on the specific MMR gene mutated [58-61] (Table 3). A large international prospective cohort study involving over 3000 patients recently found cumulative incidence of CRC (at 75 years) of $46 \%, 35 \%, 49 \%$, and $10 \%$ for MLH1, MLH2, MSH6, and PMS2 mutation carriers, respectively, after a mean follow-up period of 7.8 years [47]. Most importantly, carriers of MSH6 and PMS2 mutations were at no or very low risk of CRC before the age 
of 40 years. Other studies have confirmed that the age of CRC onset in carriers of MSH6 and PMS2 mutations was delayed by 10 years compared with carriers of MLH1 and $M L H 2$ mutations with negligible risk before the age of 40 [58,60]. The risk of developing advanced adenoma or CRC before 30 years old is extremely low in carriers of $\mathrm{MSH}$ and PMS2 mutations [60]. An annual colonoscopy in 155 males or 217 females in their 20s would prevent only one death by CRC [62]. Therefore, while it seems important to start colonoscopic surveillance at the age of 20-25 years for MLH1 and MLH2 mutation carriers, 30-35 years seems in some, but not all recent recommendations to be acceptable for MSH6 and PMS2 mutation carriers [15-17,28]. The limitation of these recommendation, once more, is the low level of evidence, especially based on prospective evaluation. That is why prospective series are still needed to precisely depict the risk of early/advanced cancer before 35 years in MSH6 and PMS2 patients.

The recommended age to start the follow-up is different according to the pathogenic variant carrier. It begins at 25 years old for $\mathrm{MLH1}$ and $\mathrm{MSH} 2$ and 35 years old for MSH6 or PMS2 mutation carriers with a low CRC risk.

Table 3. Lifetime risks of CRC at 70 years old $[4,47,59]$.

\begin{tabular}{cc}
\hline Type of Gene Mutation Carrier & Estimated Lifetime CRC Risk \\
\hline$M L H 1$ and $M S H 2$ & Ranges from 40 to $52 \%$ \\
\hline$M S H 6$ & Approximately $15 \%$ \\
\hline$P M S 2$ & Between 3 and $13 \%$ \\
\hline
\end{tabular}

- Colonoscopy intervals

An interval of 1 to 2 years between two high-quality surveillance colonoscopies is recommended in cases of LS. Without definitive scientific evidence, this question remains open and prospective studies are needed to determine whether some specific LS patients require a one-year interval. Different studies have analyzed intervals of 1, 2, or 3 years, which correspond to the practices of different European countries (1 year for Germany, 1-2 years for the Netherlands, and 2-3 years for Finland) [47,62-66].A large-scale international study involving more than 2700 LS patients with MLH1, MLH2, or MSH6 mutations, out of a total of 16,000 colonoscopies, showed no difference in cancer incidence rates or CRC stage distribution according to the three surveillance modalities [67]. In retrospective cohort studies, the mean interval between colonoscopy and CRC diagnosis was between 24 and 36 months. This suggests the interest of more than one-year intervals $[17,28,40]$. On the other hand, the overall survival rates of patients diagnosed with interval CRC in surveillance programs are excellent, exceeding 90\% [68-70].

In conclusion, precise stratification according to the type of MMR mutation is complex to implement, and a uniform interval of 2 years between each colonoscopy for any patient with LS is recommended. In high-risk CRC families, the colonoscopy interval could be one year, especially in MLH1 and MSH2 mutation carriers. Prospective studies are also underway and will be of importance.

- Quality criteria for colonoscopy

There is no strong evidence of an increased risk of metachronous CRC in patients following polyp removal or CRC resection. The cumulative risk of metachronous CRC is highly variable according to the series, ranging from $2.1 \%$ in 7.8 years of follow-up to $16 \%$ in 10 years [31,61]. There is some evidence that incomplete removal of adenomas may significantly contribute to increased risk of CRC after colonoscopy [68]. However, recent data from the PLSD show that the impact of colonoscopy with polypectomy in preventing CRC is probably less than was previously thought [38]. Colonoscopic screening at 3-year intervals reduced the CRC rate by $62 \%$ on a controlled trial between LS patients with and without screening. The overall death rates were 10 versus 26 subjects in the study and control groups $(p=0.003)$ [37]. 
The effectiveness of a follow-up program depends on the quality of the colonoscopies performed: cleanliness, completeness, and possibly the use of chromoendoscopy $[68,71,72]$. Colonoscopy is evidently less effective for cancer prevention if the procedure does not reach the caecum or if bowel preparation is inadequate. In the case of colonoscopy with suboptimal bowel preparation (Boston bowel preparation scale $<6$ or 8 ) or incomplete colonoscopy, colonoscopy must be repeated rapidly. Inadequate bowel preparation reduces the adenoma/advanced adenoma detection rate [73]. That said, the quality criteria for colonoscopies reported in recent studies are generally of a high standard and do not explain the incidence of CRC in LS cases during surveillance [74]. One possible explanation is that geography, environment, diet, and previous surgery, as well as age, gene, and gender, explain differences in the adenoma detection rate between the studies [38].

- Chromoendoscopy versus high-definition white light endoscopy

Indigo-carmine chromoendoscopy (CE) as compared with white light endoscopy (WLE) was traditionally and is still recommended for the screening of LS patients. The optimal interval between colonoscopies should be based on the quality of the previous colonoscopy: optimal preparation, complete examination, and use of $\mathrm{CE}$ are associated with reduced CRC incidence [70]. The first studies comparing CE to WLE in LS clearly advantaged CE. Three monocenter studies and one multicenter study with back-to-back design and standard definition (SD) endoscopes demonstrated that CE was superior to WLE, reporting a WLE adenoma miss-rate ranging between 52 and 74\% [75-78]. These studies are to be considered with caution as their methodology (back-to-back design) classically favors the second arm and can thus lead to overestimation of the CE effect on the WLE.

A recent randomized controlled trial showed slightly different evidence between $\mathrm{CE}$ and WLE. A study comparing a second examination with CE to a second with WLE showed no improvement in the detection of adenomas [79]. Another recent, randomized, parallel-group, multicenter study using high-definition endoscopes and experienced endoscopists showed a low and non-significant increase in adenoma detection by CE in more than 250 patients with LS ( $34.4 \%$ versus $28.1 \%, p=0.28)$ [80]. Nevertheless, the detection rate of serrated lesions was higher with CE $(37.5 \%$ versus $23.4 \%, p=0.01)$. Yet, another study showed a higher detection rate of serrated lesions, but only in the proximal colon, using CE or WLE (adenoma detection rate of 33\% versus 27\%) [81]. The adenoma detection rate in the different studies are resumed in the Table 4.

Concerning virtual $\mathrm{CE}$, there has been no clear demonstration of non-inferiority versus high-quality WLE. Some studies have shown superiority in Lynch syndrome [75,76], but others have shown inferiority versus dye-based CE [82-84]. High-quality colonoscopy has also been recognized as an essential component of successful cancer prevention in sporadic cases [85]. There is too little evidence to suggest that it may also be relevant for cancer prevention in LS patients. Quality performance indicators for colonoscopy in LS patients should at least meet or exceed those required for colonoscopy in sporadic cases. The caecal intubation rate and adenoma/polyp detection rate $(>30 \%$ for experts from the ESGE) seem essential. The use of quality scores in colonoscopy reports should be recommended [86,87].

The challenge will be to develop the most efficient technology to improve the adenoma detection rate. The visual quality of endoscopes improves with each generation; the contribution of artificial intelligence is what will probably transform the methods of endoscopic monitoring in the years to come.

Colorectal dye-based chromoendoscopy is still recommended, but high-quality, high-definition white light endoscopy could be used according to some guidelines. 
Table 4. Adenoma detection rate in the different studies with indigo-carmine chromoendoscopy or white light endoscopy.

\begin{tabular}{cccc}
\hline $\begin{array}{c}\text { Adenoma Detection Rate (\%) or Total } \\
\text { Number of Adenoma Detectedin Co- } \\
\text { lonoscopy in the Different Studies }\end{array}$ & $\begin{array}{c}\text { With Indigo-Carmine Chromo- } \\
\text { endoscopy }\end{array}$ & With White Light Endoscopy & $p$-Value \\
\hline Reference [75], Perrod et al. & $99 / 353(28 \%)$ & $60 / 211(28.4 \%)$ & $p>0.05$ \\
Reference [76] Lecomte et al. & $10 / 33(30 \%)$ proximal colon only) & $3 / 33(9 \%)$ proximal colon only & $p=0.045$ \\
Reference [77], Hüneburg R et al. & $13 / 47(27 \%)$ & $7 / 47(14 \%)$ & no significant difference \\
Reference [78], Hurlstone et al. & $52 / 16$ & $24 / 13$ & $p=0.001$ \\
Reference [79], Rahmi et al. & $32 / 78(41 \%)$ & $18 / 78(23 \%)$ & $p<0.001$ \\
Reference [80], Stoffel et al. & $5 / 28(17 \%)$ & $7 / 26(26 \%)$ & no significant difference \\
Reference [81], Rivero-Sánchez et al. & $34.4 \%$ on 128 patients & $28.1 \%$ on 128 patients & no significant difference \\
\hline
\end{tabular}

\subsection{Pancreatic Cancer Risk}

Even though the lifetime cumulative risk is below $5 \%$, LS is one of the predisposing conditions to familial pancreatic cancer [88]. French recommendations [89] consider LS as a situation justifying surveillance in specific cases:

- If only one pancreatic cancer case in the family: surveillance only of first-degree relatives;

- If more than one pancreatic cancer case in the family: surveillance of all mutation carriers.

Screening for pancreatic cancer is recommended in these cases through annual pancreatic magnetic resonance imaging (MRI) and endoscopic ultrasonography in alternation, beginning at 45 years old or 10 years before the youngest case in the family. There is still limited evidence to support these guidelines and each context must be discussed with the patient $[90,91]$.

We propose in the Table 5 a summary of the different follow-up guidelines in the Lynch syndrome.

Table 5. Summary of follow-up guidelines in Lynch syndrome cases.

\section{Indication for Surveillance}

\section{Category Modality Age to Start (years) Intervals}

$$
\begin{aligned}
& \text { MSH6 and PMS2 Colonoscopy } \\
& \text { gene, carriers }
\end{aligned}
$$
surveillance

Stomach, small search protobowel, and pancreas

Screening and eradication of

Helicobacter

American guide- Colon, all mutalines $[15,16] \quad$ tion carriers
35

No routine beside re-

$$
\text { cols. }
$$
pylori.

20 to 25 , or 5 years

2 yearly until age chromoendoscopy may be of ben75 years old 2 yearly until age 75 years old

None None

Colonoscopy before the youngest age of diagnosis of
Every 1 to 2 years
British guidelines: High-quality, high-definition white light endoscopy is the preferred modality for colonoscopy surveillance
ESGE guidelines: The use of efit in individuals with Lynch syndrome undergoing colonoscopy; however, routine use must be balanced against costs, training, and practical considerations.$$
\text { colonoscopy surveillance }
$$ 


colorectal cancer in
an affected family
member
No routine
surveillance
Stomach, small
outside clini-
cal trial.
creas pan-
$\begin{gathered}\text { Screening and } \\ \text { eradication of } \\ \text { Helicobacter } \\ \text { pylori. }\end{gathered}$

\section{Treatment of Colorectal Cancer in Lynch Syndrome}

Large intestinal lesions are now treated by endoscopy by means of endoscopic submucosal dissection (ESD) [92-94]. Even though some clinical cases report early CRC treated by ESD [95], surgical treatment is clearly the recommended option in invasive CRC, especially for lymph node dissection. For LS patients with MLH1 or MSH2mutations who develop CRC, even with adequate follow-up, the decision to perform segmental versus total/near-total colectomy should take into account the risks of metachronous CRC, the functional consequences of surgery, compliance with colonoscopy screening, and patient age and preferences. In most cases, segmental colectomy is recommended. For LS patients with MSH6 or PMS2mutations, there is insufficient evidence to perform total/near-total colectomy rather than segmental resection. This is a strong recommendation by the last scientific society to evaluate the subject [17]. In addition, when abdominal perineal excision can be avoided, standard low anterior resection is a reasonable option to treat rectal cancers in LS patients, even though the residual colon is at risk of metachronous neoplasia [17].

\section{Patient Adherence in Endoscopic Follow-Up Program}

The LS patient's adherence in repeated colonoscopies is challenging, but necessary to prevent colorectal neoplasia. While most individuals continue to engage in follow-up programs over the long term, about $20 \%$ have a partial or complete rupture with endoscopic follow-up [96]. In addition, a quarter of them require psychosocial support because of developing moderate depressive symptoms [97]. A clear and repeated explanation of the value of endoscopic surveillance in effectively preventing CRC risk is the key to successful adherence to surveillance programs. Specialized programs to remind patients of the dates of exams and follow-up are useful to avoid delays in colonoscopies.

The impact of a lifestyle change on people with familial risk is being evaluated and the concerned individuals may benefit from an explanation of these modifiable risk factors in order to adapt their lifestyle and, thereby, potentially reduce their level of adenoma/CRC risk [98-100]. Furthermore, there is evidence that smokers, particularly men with MLH1 mutation and overweight/obesity, have an increased risk of CRC [101,102]. Nevertheless, the effect of patient education on increased adherence to the endoscopic follow-up program is not clearly proven. In a study on family communication in LS, patients who received educational resources had a higher likelihood of following up with a doctor and pursuing genetic testing than families without educational resources [103]. Educational workshop and support groups in LS have been evaluated in one study and a large majority of their participants perceived them as really helpful [104]. The spread of such programs could be one of the solutions to motivate LS patients to join the endoscopic surveillance program.

To improve patient adherence to endoscopic follow-up programs, it seems necessary to explain the benefits of the colonoscopies on their future life and to include them in dedicated education programs. 


\section{Conclusions}

The first challenge is to properly identify patients with Lynch syndrome. Systematic MSI testing and/or loss of expression of MMR proteins in IHC for all CRCs is probably one of the most efficient approaches to be developed. Once the diagnosis has been clarified, several guidelines for screening and follow-up programs are now available. Discrepancies in these recommendations exist, with still limited prospective scientific evidence on some points. After reviewing the various literature and studies, we could nevertheless propose some clear recommendations for Lynch syndrome patients.

- Routine gastric surveillance does not seem necessary owing to the low gastric cancer risk.HP screening should be systematically performed.

- There is currently not enough evidence to recommend routine small bowel monitoring, including by VCE.

- The recommended follow-up for colonoscopy begins at 20-25 years-old for MLH1 and $\mathrm{MSH} 2$ pathogenic variant carriers and 30-35 years-old for MSH6 or PMS2 mutation carriers.

- A uniform interval of 2 years between each colonoscopy is recommended. In high-risk CRC families, the colonoscopy interval could be one year, especially in $M L H 1$ and $M S H 2$ mutation carriers.

- Colorectal dye-based chromoendoscopy is still recommended, but high-quality, high-definition white light endoscopy could be used according to some guidelines.

- Surgical treatment is still clearly the recommended option in the case of invasive CRC.

- The patients should be followed in appropriate centers and specialized networks.Improved adherence of the patient to a screening program also seems essential.

The technology is constantly improving, as is the adenoma detection rate. The visual quality of endoscopes improves with each generation, and virtual dyes and artificial intelligence will probably transform our practices and endoscopic monitoring in the years to come.

Author Contributions: Conceptualization, R.O. and J.-C.S.; methodology, R.O. and V.R.; validation J.-C.S. and D.T; writing R.O. All authors have read and agreed to the published version of the manuscript.

Funding: This research received no external funding.

Conflicts of Interest: The authors declare no conflict of interest.

\begin{tabular}{ll} 
Abbreviations & \\
\hline ACPGBI & $\begin{array}{l}\text { Association of Coloproctology of Great Britain and Ireland } \\
\text { British Society of Gastroenterology } \\
\text { BSG }\end{array}$ \\
cE & $\begin{array}{l}\text { colorectal cancer } \\
\text { mismatch repair deficiency }\end{array}$ \\
CRC & epithelial cell adhesion molecule \\
dMMR & endoscopic submucosal dissection \\
EPCAM & European Society of Gastrointestinal Endoscopy \\
ESD & Helicobacter pylori \\
ESGE & immunohistochemistry \\
HP & Lynch syndrome \\
IHC & mismatch repair \\
LS & magnetic resonance imaging \\
MMR & microsatellite instability \\
MRI & non-steroidal anti-inflammatory drugs \\
MSI & Prospective Lynch Syndrome Database \\
NSAIDs &
\end{tabular}




\begin{tabular}{ll}
\hline SBA & small bowel adenocarcinoma \\
SD & standard definition \\
SSL & sessile serrated lesions \\
UKCGG & United Kingdom Cancer Genetics Group \\
VCE & video-capsule endoscopy \\
WLE & white light endoscopy \\
\hline
\end{tabular}

\section{References}

1. Lichtenstein, P.; Holm, N.V.; Verkasalo, P.K.; Iliadou, A.; Kaprio, J.; Koskenvuo, M.; Pukkala, E.; Skytthe, A.; Hemminki, K. Environmental and Heritable Factors in the Causation of Cancer-Analyses of Cohorts of Twins from Sweden, Denmark, and Finland. N. Engl. J. Med. 2000, 343, 78-85, doi:10.1056/nejm200007133430201.

2. Jasperson, K.W.; Tuohy, T.M.; Neklason, D.W.; Burt, R.W. Hereditary and Familial Colon Cancer. Gastroenterology 2010, 138, 2044-2058, doi:10.1053/j.gastro.2010.01.054.

3. Bucksch, K.; Zachariae, S.; Aretz, S.; Büttner, R.; Holinski-Feder, E.; Holzapfel, S.; Hüneburg, R.; Kloor, M.; Doeberitz, M.V.K.; Morak, M.; et al. Cancer risks in Lynch syndrome, Lynch-like syndrome, and familial colorectal cancer type X: A prospective cohort study. BMC Cancer 2020, 20, 1-11, doi:10.1186/s12885-020-06926-x.

4. Dominguez-Valentin, M.; Sampson, J.R.; Seppälä, T.T.; Ten Broeke, S.W.; Plazzer, J.-P.; Nakken, S.; Engel, C.; Aretz, S.; Jenkins, M.A.; Sunde, L.; et al. Cancer risks by gene, age, and gender in 6350 carriers of pathogenic mismatch repair variants: Findings from the Prospective Lynch Syndrome Data-base. Genet. Med. 2020, 22, 15-25.

5. Hampel, H.; Frankel, W.L.; Martin, E.; Arnold, M.; Khanduja, K.; Kuebler, P.; Clendenning, M.; Sotamaa, K.; Prior, T.; Westman, J.A.; et al. Feasibility of Screening for Lynch Syndrome Among Patients With Colorectal Cancer. J. Clin. Oncol. 2008, 26, 5783-5788, doi:10.1200/jco.2008.17.5950.

6. Buecher, B.; Cacheux, W.; Rouleau, E.; Dieumegard, B.; Mitry, E.; Lièvre, A. Role of microsatellite instability in the management of colorectal cancers. Dig. Liver Dis. 2013, 45, 441-449, doi:10.1016/j.dld.2012.10.006.

7. Tougeron, D.; Sickersen, G.; Mouillet, G.; Zaanan, A.; Trouilloud, I.; Coriat, R.; Aparicio, T.; Guetz, G.D.; Lecaille, C.; Artru, P.; et al. Predictors of disease-free survival in colorectal cancer with microsatellite instability: An AGEO multicentre study. Eur. J. Cancer 2015, 51, 925-934, doi:10.1016/j.ejca.2015.03.011.

8. Tougeron, D.; Mouillet, G.; Trouilloud, I.; Lecomte, T.; Coriat, R.; Aparicio, T.; Guetz, G.D.; Lécaille, C.; Artru, P.; Sickersen, G.; et al. Efficacy of Adjuvant Chemotherapy in Colon Cancer with Microsatellite Instability: A Large Multicenter AGEO Study. J. Natl. Cancer Inst. 2016, 108, djv438, doi:10.1093/jnci/djv438.

9. Tougeron, D.; Sueur, B.; Zaanan, A.; de la Fouchardiére, C.; Sefrioui, D.; Lecomte, T.; Aparicio, T.; Des Guetz, G.; Artru, P.; Hautefeuille, V.; et al. Prognosis and chemosensitivity of deficient MMR phenotype in patients with metastatic colorectal cancer: An AGEO retrospective multicenter study. Int. J. Cancer 2020, 147, 285-2196.

10. André, T.; Shiu, K.-K.; Kim, T.W.; Jensen, B.V.; Jensen, L.H.; Punt, C.; Smith, D.; Garcia-Carbonero, R.; Benavides, M.; Gibbs, P.; et al. Pembrolizumab in Microsatellite-Instability-High Advanced Colorectal Cancer. N. Engl. J. Med. 2020, 383, $2207-2218$.

11. Collura, A.; Lefevre, J.H.; Svrcek, M.; Tougeron, D.; Zaanan, A.; Duval, A. Microsatellite instability and cancer: From genomic in-stability to personalized medicine. Med. Sci. 2019, 35, 535-543.

12. Umar, A.; Boland, C.R.; Terdiman, J.P.; Syngal, S.; De La Chapelle, A.; Rüschoff, J.; Fishel, R.; Lindor, N.M.; Burgart, L.J.; Hamelin, R.; et al. Revised Bethesda Guidelines for Hereditary Nonpolyposis Colorectal Cancer (Lynch Syndrome) and Microsatellite Instability. J. Natl. Cancer Inst. 2004, 96, 261-268, doi:10.1093/jnci/djh034.

13. Vasen, H.; Watson, P.; Mecklin, J.-P.; Lynch, H.T. New clinical criteria for hereditary nonpolyposis colorectal cancer (HNPCC, Lynch syndrome) proposed by the International Collaborative Group on HNPCC. Gastroenterol. 1999, 116, 1453-1456, doi:10.1016/s0016-5085(99)70510-x.

14. Vasen, H.F.; Blanco, I.; Aktan-Collan, K.; Gopie, J.P.; Alonso, A.; Aretz, S.; Bernstein, I.; Bertario, L.; Burn, J.; Capella, G.; et al. Revised guidelines for the clinical management of Lynch syndrome (HNPCC): Recommendations by a group of European experts. Gut 2013, 62, 812-823, doi:10.1136/gutjnl-2012-304356.

15. Gupta, S.; Provenzale, D.; Llor, X.; Halverson, A.L.; Grady, W.; Chung, D.C.; Haraldsdottir, S.; Markowitz, A.J.; Slavin, T.P., Jr.; Hampel, H.; et al. NCCN Guidelines Insights: Genetic/Familial High-Risk Assessment: Colorectal, Version 2.2019. J. Natl. Compr. Cancer Netw. 2019, 17, 1032-1041, doi:10.6004/jnccn.2019.0044.

16. Rubenstein, J.H.; Enns, R.; Heidelbaugh, J.; Barkun, A.; Adams, M.; Dorn, S.D.; Dudley-Brown, S.L.; Flamm, S.L.; Gellad, Z.F.; Gruss, C.B.; et al. American Gastroenterological Association Institute Guideline on the Diagnosis and Management of Lynch Syndrome. Gastroenterology 2015, 149, 777-782, doi:10.1053/j.gastro.2015.07.036.

17. Monahan, K.J.; Bradshaw, N.; Dolwani, S.; Desouza, B.; Dunlop, M.G.; East, J.E.; Ilyas, M.; Kaur, A.; Lalloo, F.; Latchford, A.; et al. Guidelines for the management of hereditary colorectal cancer from the British Society of Gastroenterology (BSG)/Association of Coloproctology of Great Britain and Ire-land (ACPGBI)/United Kingdom Cancer Genetics Group (UKCGG). Gut 2020, 69, 411-444.

18. Aaltonen, L.A.; Salovaara, R.; Kristo, P.; Canzian, F.; Hemminki, A.; Peltomäki, P.; Chadwick, R.B.; Kääriäinen, H.; Eskelinen, M.; Järvinen, H.; et al. Incidence of hereditary nonpolyposis colorectal cancer and the feasibility of molecular screening for the disease. N. Engl. J. Med. 1998, 338, 1481-1487. 
19. Boland, C.R.; Thibodeau, S.N.; Hamilton, S.R.; Sidransky, D.; Eshleman, J.R.; Burt, R.W.; Meltzer, S.J.; Rodriguez-Bigas, M.A.; Fodde, R.; Ranzani, G.N.; et al. A National Cancer Institute Workshop on Microsatellite Instability for cancer detection and familial predisposition: Development of international criteria for the de-termination of microsatellite instability in colorectal cancer. Cancer Res. 1998, 58, 5248-5257.

20. Suraweera, N.; Duval, A.; Reperant, M.; Vaury, C.; Furlan, D.; Leroy, K.; Seruca, R.; Iacopetta, B.; Hamelin, R. Evaluation of tumor microsatellite instability using five quasimonomorphic mononucleotide repeats and pentaplex PCR. Gastroenterology 2002, 123, 1804-1811, doi:10.1053/gast.2002.37070.

21. Leclerc, J.; Vermaut, C.; Buisine, M.-P. Diagnosis of Lynch Syndrome and Strategies to Distinguish Lynch-Related Tumors from Sporadic MSI/dMMR Tumors. Cancers 2021, 13, 467, doi:10.3390/cancers13030467.

22. Chen, M.-L.; Chen, J.-Y.; Hu, J.; Chen, Q.; Yu, L.-X.; Liu, B.-R.; Qian, X.-P.; Yang, M. Comparison of microsatellite status detection methods in colorectal carcinoma. Int. J. Clin. Exp. Pathol. 2018, 11, 1431-1438.

23. Watson, N.; Grieu, F.; Morris, M.; Harvey, J.; Stewart, C.; Schofield, L.; Goldblatt, J.; Iacopetta, B. Heterogeneous Staining for Mismatch Repair Proteins during Population-Based Prescreening for Hereditary Nonpolyposis Colorectal Cancer. J. Mol. Diagn. 2007, 9, 472-478, doi:10.2353/jmoldx.2007.060162.

24. De Salins, A.G.; Tachon, G.; Cohen, R.; Karayan-Tapon, L.; Junca, A.; Frouin, E.; Godet, J.; Evrard, C.; Randrian, V.; Duval, A.; et al. Discordance between immunochemistry of mismatch repair proteins and molecular testing of microsatellite instability in colorectal cancer. ESMO Open 2021, 6, 100120.

25. Buchanan, D.D.; Tan, Y.Y.; Walsh, M.D.; Clendenning, M.; Metcalf, A.M.; Ferguson, K.; Arnold, S.T.; Thompson, B.A.; Lose, F.A.; Parsons, M.T.; et al. Tumor mismatch repair immunohisto-chemistry and DNA MLH1 methylation testing of patients with endometrial cancer diagnosed at age younger than 60 years optimizes triage for population-level germline mismatch repair gene mutation testing. J. Clin. Oncol. 2014, 32, 90-100.

26. Beamer, L.C.; Grant, M.L.; Espenschied, C.R.; Blazer, K.R.; Hampel, H.L.; Weitzel, J.N.; MacDonald, D.J. Reflex immunohistochemistry and microsatellite instability testing of colorectal tumors for Lynch syndrome among US cancer programs and follow-up of abnormal results. J. Clin. Oncol. 2012, 30, 1058-1063.

27. De Jong, A.E.; Morreau, H.; Van Puijenbroek, M.; Eilers, P.H.; Wijnen, J.; Nagengast, F.M.; Griffioen, G.; Cats, A.; Menko, F.H.; Kleibeuker, J.H.; et al. The role of mismatch repair gene defects in the development of adenomas in patients with HNPCC. Gastroenterology 2004, 126, 42-48.

28. Van Leerdam, M.E.; Roos, V.H.; van Hooft, J.E.; Balaguer, F.; Dekker, E.; Kaminski, M.F.; Latchford, A.; Neumann, H.; Ricciardiello, L.; Rupińska, M.; et al. Endoscopic management of Lynch syndrome and of familial risk of colorectal cancer: European Society of Gastrointestinal Endoscopy (ESGE) Guideline. Endoscopy 2019, 51, 1082-1093.

29. Järvinen, H.J.; Mecklin, J.P.; Sistonen, P. Screening reduces colorectal cancer rate in families with hereditary nonpolyposis colorectal cancer. Gastroenterology 1995, 108, 1405-1411.

30. De Jong, A.E.; Hendriks, Y.M.C.; Kleibeuker, J.H.; de Boer, S.Y.; Cats, A.; Griffioen, G.; Nagengast, F.M.; Nelis, F.G.; Rookus, M.A.; Vasen, H.F. Decrease in mortality in Lynch syndrome families because of surveillance. Gastroenterology 2006, 130, $665-671$.

31. Järvinen, H.J.; Aarnio, M.; Mustonen, H.K.; Aktan-Collanł, K.; Aaltonen, L.; Peltomäki§, P.; De La Chapelle§, A.; Mecklin, J.-P. Controlled 15-year trial on screening for colorectal cancer in families with hereditary nonpolyposis colorectal cancer. Gastroenterology 2000, 118, 829-834, doi:10.1016/s0016-5085(00)70168-5.

32. Stoffel, E.M.; Mercado, R.C.; Kohlmann, W.; Ford, B.; Grover, S.; Conrad, P.; Blanco, A.; Shannon, K.M.; Powell, M.; Chung, D.C.; et al. Prevalence and predictors of appropriate colorectal cancer surveillance in Lynch syndrome. Am. J. Gastroenterol. 2010, 105, 1851-1860.

33. Sjöström, O.; Lindholm, L.; Tavelin, B.; Melin, B. Decentralized colonoscopic surveillance with high patient compliance prevents hereditary and familial colorectal cancer. Fam. Cancer 2016, 15, 543-551, doi:10.1007/s10689-016-9867-7.

34. Schneider, J.L.; Goddard, K.A.B.; Muessig, K.R.; Davis, J.V.; Rope, A.F.; Hunter, J.E.; Peterson, S.K.; Acheson, L.S.; Syngal, S.; Wiesner, G.L.; et al. Patient and provider perspectives on adherence to and care coordination of lynch syndrome surveillance recommendations: Findings from qualitative interviews. Hered. Cancer Clin. Pract. 2018, 16, 11.

35. de Jong, A.E.; Nagengast, F.M.; Kleibeuker, J.H.; van de Meeberg, P.C.; van Wijk, H.J.; Cats, A.; Griffioen, G.; Vasen, H.F. What is the appropriate screening protocol in Lynch syndrome? Fam. Cancer 2006, 5, 373-378.

36. Anyla, M.; Lefevre, J.H.; Creavin, B.; Colas, C.; Svrcek, M.; Lascols, O.; Debove, C.; Chafai, N.; Tiret, E.; Parc, Y. Metachronous colorectal cancer risk in Lynch syndrome patients-should the endoscopic surveillance be more intensive? Int. J. Color. Dis. 2018, 33, 703-708, doi:10.1007/s00384-018-3004-z.

37. Kaminski, M.F.; Thomas-Gibson, S.; Bugajski, M.; Bretthauer, M.; Rees, C.J.; Dekker, E.; Hoff, G.; Jover, R.; Suchanek, S.; Ferlitsch, M.; et al. Performance measures for lower gastro-intestinal endoscopy: A European Society of Gastrointestinal Endoscopy (ESGE) Quality Improvement Initiative. Endoscopy 2017, 49, 378-397.

38. Seppälä, T.T.; Dominguez-Valentin, M.; Sampson, J.R.; Møller, P. Prospective observational data informs understanding and fu-ture management of Lynch syndrome: Insights from the Prospective Lynch Syndrome Database (PLSD). Fam. Cancer 2021, 20,35-39.

39. Barrow, E.; Hill, J.; Evans, G. Cancer risk in Lynch Syndrome. Fam. Cancer 2013, 12, 229-240, doi:10.1007/s10689-013-9615-1.

40. Galiatsatos, P.; Labos, C.; Jeanjean, M.; Miller, K.; Foulkes, W.D. Low yield of gastroscopy in patients with Lynch syndrome. Turk. J. Gastroenterol. 2017, 28, 434-438, doi:10.5152/tjg.2017.17176. 
41. Soer, E.C.; Leicher, L.W.; Langers, A.M.J.; van de Meeberg, P.C.; van der Wouden, E.-J.; Koornstra, J.J.; Bigirwamungu-Bargeman, M.; Vasen, H.F.; tot Nederveen, W.H. Equivalent Helicobacter pylori infection rates in Lynch syndrome mutation carriers with and without a first-degree relative with gastric cancer. Int. J. Colorectal. Dis. 2016, 31, 693-697.

42. Renkonen-Sinisalo, L.; Sipponen, P.; Aarnio, M.; Julkunen, R.; Aaltonen, L.A.; Sarna, S.; Järvinen, H.J.; Mecklin, J.-P. No support for endoscopic surveillance for gastric cancer in hereditary non-polyposis colorectal cancer. Scand. J. Gastroenterol. 2002, 37, 574-577, doi:10.1080/00365520252903134.

43. Fuccio, L.; Zagari, R.M.; Minardi, M.E.; Bazzoli, F. Systematic review: Helicobacter pylori eradication for the prevention of gastric cancer. Aliment. Pharmacol. Ther. 2006, 25, 133-141, doi:10.1111/j.1365-2036.2006.03183.x.

44. Lansdorp-Vogelaar, I.; Sharp, L. Cost-effectiveness of screening and treating Helicobacter pylori for gastric cancer prevention. Best Pr. Res. Clin. Gastroenterol. 2013, 27, 933-947, doi:10.1016/j.bpg.2013.09.005.

45. Choi, I.J.; Kim, C.G.; Lee, J.Y.; Kim, Y.-I.; Kook, M.-C.; Park, B.; Joo, J. Family History of Gastric Cancer and Helicobacter pylori Treatment. N. Engl. J. Med. 2020, 382, 427-436.

46. TenKate, G.L.; Kleibeuker, J.H.; Nagengast, F.M.; Craanen, M.; Cats, A.; Menko, F.H.; Vasen, H.F. Is surveillance of the small bowel indicated for Lynch syndrome families? Gut 2007, 56, 1198-1201.

47. Møller, P.; Seppälä, T.T.; Bernstein, I.; Holinski-Feder, E.; Sala, P.; Gareth Evans, D.; Lindblom, A.; Macrae, F.; Blanco, I.; Sijmons, R.H.; et al. Cancer risk and survival in path_MMR carriers by gene and gender up to 75 years of age: A report from the Prospective Lynch Syndrome Database. Gut 2018, 67, 1306-1316.

48. Lynch, H.T.; Smyrk, T.C.; Jd, P.M.L.; Lanspa, S.J.; Boman, B.M.; Ens, J.; Lynch, J.F.; Rn, P.S.; Bs, T.C.; Cristofaro, G. Adenocarcinoma of the small bowel in Lynch syndrome II. Cancer 1989, 64, 2178-2183, doi:10.1002/1097-0142(19891115)64:103.0.co;2-0.

49. Rodriguez-Bigas, M.A.; Vasen, H.; Lynch, H.T.; Watson, P.; Järvinen, H.J.; Mecklin, J.P.; Macrae, F.; John, D.J.B.S.; Bertario, L.; Fidalgo, P.; et al. Characteristics of small bowel carcinoma in hereditary nonpolyposis colorectal carcinoma. Cancer 1998, 83, 240-244, doi:10.1002/(sici)1097-0142(19980715)83:23.0.co;2-u.

50. Schulmann, K.; Brasch, F.E.; Kunstmann, E.; Engel, C.; Pagenstecher, C.; Vogelsang, H.; Krüger, S.; Vogel, T.; Knaebel, H.P.; Rüschoff, J.; et al. HNPCC-associated small bowel cancer: Clinical and molecular characteristics. Gastroenterology 2005, 128, 590-599.

51. Park, J.-G.; Kim, D.-W.; Hong, C.W.; Nam, B.-H.; Shin, Y.-K.; Hong, S.-H.; Kim, I.J.; Lim, S.B.; Aronson, M.; Bisgaard, M.L.; et al. Germ line mutations of mismatch repair genes in hereditary nonpolyposis colorectal cancer patients with small bowel cancer: International Society for Gastrointestinal Hereditary Tumours Collaborative Study. Clin. Cancer Res. 2006, 12, $3389-3393$.

52. Aparicio, T.; Zaanan, A.; Svrcek, M.; Laurent-Puig, P.; Carrere, N.; Manfredi, S.; Locher, C.; Afchain, P. Small bowel adenocarcinoma: Epidemiology, risk factors, diagnosis and treatment. Dig. Liver Dis. 2014, 46, 97-104, doi:10.1016/j.dld.2013.04.013.

53. Haanstra, J.F.; Al-Toma, A.; Dekker, E.; Vanhoutvin, S.A.L.W.; Nagengast, F.M.; Mathus-Vliegen, E.M.; Van Leerdam, M.E.; Cappel, W.H.D.V.T.N.; Sanduleanu, S.; Veenendaal, R.A.; et al. Prevalence of small-bowel neoplasia in Lynch syndrome assessed by video capsule endoscopy. Gut 2015, 64, 1578-1583, doi:10.1136/gutjnl-2014-307348.

54. Saurin, J.-C.; Pilleul, F.; Soussan, E.B.; Manière, T.; D’Halluin, P.N.; Gaudric, M.; Cellier, C.; Heresbach, D.; Gaudin, J.L.; Capsule Commission of the French Society of Digestive Endoscopy (SFED). Small-bowel capsule endoscopy diagnoses early and advanced neoplasms in asymptomatic patients with Lynch syndrome. Endoscopy 2010, 42, 1057-1062, doi:10.1055/s-0030-1255742.

55. Haanstra, J.F.; Al-Toma, A.; Dekker, E.; Vanhoutvin, S.A.; Nagengast, F.M.; Mathus-Vliegen, E.M.; Van Leerdam, M.E.; tot Nederveen, W.H.; Veenendaal, R.A.; Cats, A.; et al. Incidence of small bowel neoplasia in Lynch syndrome assessed by video capsule endoscopy. Endosc. Int. Open 2017, 5, E622-E626, doi:10.1055/s-0043-111723.

56. Vleugels, J.L.; Sahin, H.; Hazewinkel, Y.; Koens, L.; Berg, J.G.V.D.; van Leerdam, M.E.; Dekker, E. Endoscopic detection rate of sessile serrated lesions in Lynch syndrome patients is comparable with an age- and gender-matched control population: Case-control study with expert pathology review. Gastrointest. Endosc. 2018, 87, 1289-1296, doi:10.1016/j.gie.2017.11.034.

57. Rondagh, E.J.A.; Gulikers, S.; Gomez-Garcia, E.; Vanlingen, Y.; Detisch, Y.; Winkens, B.; Vasen, H.; Masclee, A.A.M.; Sanduleanu-Dascalescu, S. Nonpolypoid colorectal neoplasms: A challenge in endoscopic surveillance of patients with Lynch syndrome. Endoscopy 2013, 45, 257-264, doi:10.1055/s-0032-1326195.

58. Hendriks, Y.M.C.; Wagner, A.; Morreau, H.; Menko, F.; Stormorken, A.; Quehenberger, F.; Sandkuijl, L.; Møller, P.; Genuardi, M.; Van Houwelingen, H.; et al. Cancer risk in hereditary nonpolyposis colorectal cancer due to MSH6 mutations: Impact on counseling and surveillance. Gastroenterology 2004, 127, 17-25.

59. Ten Broeke, S.W.; van der Klift, H.M.; Tops, C.M.J.; Aretz, S.; Bernstein, I.; Buchanan, D.D.; de la Chapelle, A.; Capella, G.; Clendenning, M.; Engel, C.; et al. Cancer Risks for PMS2-Associated Lynch Syndrome. J. Clin. Oncol. 2018, 36, $2961-2968$.

60. Plaschke, J.; Engel, C.; Krüger, S.; Holinski-Feder, E.; Pagenstecher, C.; Mangold, E.; Moeslein, G.; Schulmann, K.; Gebert, J.; Doeberitz, M.V.K.; et al. Lower Incidence of Colorectal Cancer and Later Age of Disease Onset in 27 Families With Pathogenic MSH6 Germline Mutations Compared With Families with MLH1 or MSH2 Mutations: The German Hereditary Nonpolyposis Colorectal Cancer Consortium. J. Clin. Oncol. 2004, 22, 4486-4494, doi:10.1200/jco.2004.02.033.

61. Engel, C.; Ahadova, A.; Seppälä, T.T.; Aretz, S.; Bigirwamungu-Bargeman, M.; Bläker, H.; Bucksch, K.; Büttner, R.; tot Nederveen, W.T.; Endris, V.; et al. Associations of Pathogenic Variants in MLH1, MSH2, and MSH6 with Risk of Colorectal Adenomas and Tumors and With Somatic Mutations in Patients With Lynch Syndrome. Gastroenterology 2020, 158, $1326-1333$.

62. Jenkins, M.A.; Dowty, J.G.; Ait Ouakrim, D.; Mathews, J.D.; Hopper, J.L.; Drouet, Y.; Lasset, C.; Bonadona, V.; Win, A.K. Short-term risk of colorectal cancer in individuals with lynch syndrome: A meta-analysis. J. Clin. Oncol. 2015, 33, 326-331. 
63. Ramsoekh, D.; Wagner, A.; E. Van Leerdam, M.; Dooijes, D.; Tops, C.M.; Steyerberg, E.W.; Kuipers, E.J. Cancer risk in MLH1, MSH2 and MSH6 mutation carriers; different risk profiles may influence clinical management. Hered. Cancer Clin. Pr. 2009, 7, 17, doi:10.1186/1897-4287-7-17.

64. Edelstein, D.L.; Axilbund, J.; Baxter, M.; Hylind, L.M.; Romans, K.; Griffin, C.A.; Cruz-Correa, M.; Giardiello, F.M. Rapid Development of Colorectal Neoplasia in Patients With Lynch Syndrome. Clin. Gastroenterol. Hepatol. 2011, 9, 340-343, doi:10.1016/j.cgh.2010.10.033.

65. Vasen, H.F.A.; Abdirahman, M.; Brohet, R.; Langers, A.M.J.; Kleibeuker, J.H.; van Kouwen, M.; Koornstra, J.J.; Boot, H.; Cats, A.; Dekker, E.; et al. One to 2-year surveillance intervals reduce risk of colorectal cancer in families with Lynch syndrome. Gastroenterology 2010, 138, 2300-2306.

66. Lamba, M.; Ebel, R.; Hamilton, S.; Frampton, C.; Wakeman, C.; Kiesanowski, M.; Griffiths, B.; Keating, J.; Bergman, R.; Ow, M.; et al. 828-What's My Risk of Cancer Doctor? In-terval Colorectal Cancer Risk in Lynch Syndrome: Results from the New Zealand National Registry. Gastroenterology 2019, 156, S179.

67. Engel, C.; Vasen, H.F.; Seppälä, T.; Aretz, S.; Bigirwamungu-Bargeman, M.; de Boer, S.Y.; Bucksch, K.; Büttner, R.; Holinski-Feder, E.; Holzapfel, S.; et al. No Difference in Colorectal Cancer Incidence or Stage at Detection by Colonoscopy among 3 Countries with Different Lynch Syndrome Surveillance Policies. Gastroenterology 2018, 155, 1400-1409.e2.

68. Haanstra, J.F.; Vasen, H.F.A.; Sanduleanu, S.; Van Der Wouden, E.J.; Koornstra, J.J.; Kleibeuker, J.H.; Cappel, W.H.D.V.T.N. Quality colonoscopy and risk of interval cancer in Lynch syndrome. Int. J. Color. Dis. 2013, 28, 1643-1649, doi:10.1007/s00384-013-1745-2.

69. Seppälä, T.; Pylvänäinen, K.; Evans, D.G.; Järvinen, H.; Renkonen-Sinisalo, L.; Bernstein, I.; Holinski-Feder, E.; Sala, P.; Lindblom, A.; Macrae, F.; et al. Colorectal cancer incidence in path_MLH1 carriers subjected to different follow-up protocols: A Prospective Lynch Syndrome Database report. Hered. Cancer Clin. Pract. 2017, 15, 18.

70. Stupart, D.A.; Goldberg, P.; Algar, U.; Ramesar, R. Surveillance colonoscopy improves survival in a cohort of subjects with a single mismatch repair gene mutation. Color. Dis. 2009, 11, 126-130, doi:10.1111/j.1463-1318.2008.01702.x.

71. Parry, S.; Win, A.; Parry, B.; A. Macrae, F.; Gurrin, L.C.; Church, J.M.; A. Baron, J.; Giles, G.; Leggett, B.; Winship, I.; et al. Metachronous colorectal cancer risk for mismatch repair gene mutation carriers: The advantage of more extensive colon surgery. Gut 2010, 60, 950-957, doi:10.1136/gut.2010.228056.

72. Bisschops, R.; East, J.E.; Hassan, C.; Hazewinkel, Y.; Kamiński, M.F.; Neumann, H.; Pellisé, M.; Antonelli, G.; Balen, M.B.; Coron, E.; et al. Advanced imaging for detection and differentiation of colorectal neoplasia: European Society of Gastrointestinal Endoscopy (ESGE) Guideline-Update 2019. Endoscopy 2019, 51, 1155-1179.

73. Clark, B.T.; Rustagi, T.; Laine, L. What level of bowel prep quality requires early repeat colonoscopy: Systematic review and me-ta-analysis of the impact of preparation quality on adenoma detection rate? Am. J. Gastroenterol. 2014, 109, 1714-1723.

74. Lappalainen, J.; Holmström, D.; Lepistö, A.; Saarnio, J.; Mecklin, J.-P.; Seppälä, T. Incident colorectal cancer in Lynch syndrome is usually not preceded by compromised quality of colonoscopy. Scand. J. Gastroenterol. 2019, 54, 1473-1480.

75. Perrod, G.; Samaha, E.; Rahmi, G.; Khater, S.; Abbes, L.; Savale, C.; Perkins, G.; Zaanan, A.; Chatellier, G.; Malamut, G.; et al. Impact of an optimized colonoscopic screening program for patients with Lynch syndrome: 6-year results of a specialized French network. Ther. Adv. Gastroenterol. 2018, 11, doi:10.1177/1756284818775058.

76. Lecomte, T.; Cellier, C.; Meatchi, T.; Barbier, J.P.; Cugnenc, P.H.; Jian, R.; Laurent-Puig, P.; Landi, B. Chromoendoscopic colonoscopy for detecting preneoplastic lesions in hereditary nonpolyposis colorectal cancer syndrome. Clin. Gastroenterol. Hepatol. 2005, 3, 897-902.

77. Hüneburg, R.; Lammert, F.; Rabe, C.; Rahner, N.; Kahl, P.; Büttner, R.; Propping, P.; Sauerbruch, T.; Lamberti, C. Chromocolonoscopy detects more adenomas than white light colonoscopy or narrow band imaging colonoscopy in hereditary nonpolyposis colorectal cancer screening. Endoscopy 2009, 41, 316-322, doi:10.1055/s-0028-1119628.

78. Hurlstone, D.P.; Karajeh, M.; Cross, S.S.; E. McAlindon, M.; Brown, S.; Hunter, M.D.; Sanders, D.S. The Role of High-Magnification-Chromoscopic Colonoscopy in Hereditary Nonpolyposis Colorectal Cancer Screening: A Prospective "Back-to-Back" Endoscopic Study. Am. J. Gastroenterol. 2005, 100, 2167-2173, doi:10.1111/j.1572-0241.2005.41481.x.

79. Rahmi, G.; Lecomte, T.; Malka, D.; Maniere, T.; Le Rhun, M.; Guimbaud, R.; Lapalus, M.-G.; Le Sidaner, A.; Moussata, D.; Caron, O.; et al. Impact of Chromoscopy on Adenoma Detection in Patients With Lynch Syndrome: A Prospective, Multicenter, Blinded, Tandem Colonoscopy Study. Am. J. Gastroenterol. 2015, 110, 288-298, doi:10.1038/ajg.2014.423.

80. Stoffel, E.M.; Turgeon, D.K.; Stockwell, D.H.; Zhao, L.; Normolle, D.P.; Tuck, M.K.; Bresalier, R.S.; Marcon, N.E.; Baron, J.A.; Ruffin, M.T.; et al. Missed adenomas during colonoscopic surveillance in individuals with Lynch Syndrome (hereditary nonpolyposis colorectal cancer). Cancer Prev. Res. 2008, 1, 470-475.

81. Rivero-Sánchez, L.; Arnau-Collell, C.; Herrero, J.; Remedios, D.; Cubiella, J.; García-Cougil, M.; Alvarez, V.; Albéniz, E.; Calvo, P.; Gordillo, J.; et al. White-Light Endoscopy Is Adequate for Lynch Syndrome Surveillance in a Randomized and Noninferiority Study. Gastroenterology 2020, 158, 895-904.e1.

82. Haanstra, J.F.; Dekker, E.; Cats, A.; Nagengast, F.M.; Hardwick, J.C.; Vanhoutvin, S.A.; tot Nederveen, W.H.; Vasen, H.F.; Kleibeuker, J.H.; Koornstra, J.J. Effect of chromoendoscopy in the proximal colon on colorectal neoplasia detection in Lynch syndrome: A multicenter randomized controlled trial. Gastrointest. Endosc. 2019, 90, 624-632.

83. Bisschops, R.; Tejpar, S.; Willekens, H.; De Hertogh, G.; Van Cutsem, E. Virtual chromoendoscopy (I-SCAN) detects more polyps in patients with Lynch syndrome: A randomized controlled crossover trial. Endoscopy 2017, 49, 342-350, doi:10.1055/s-0042-121005. 
84. East, J.E.; Suzuki, N.; Stavrinidis, M.; Guenther, T.; Thomas, H.J.W.; Saunders, B.P. Narrow band imaging for colonoscopic surveillance in hereditary nonpolyposis colorectal cancer. Gut 2008, 57, 65-70.

85. Cellier, C.; Perrod, G.; Colas, C.; Dhooge, M.; Saurin, J.-C.; Lecomte, T.; Coron, E.; Rahmi, G.; Savale, C.; Chaussade, S.; et al. Back-to-Back Comparison of Colonoscopy with Virtual Chromoendoscopy Using a Third-Generation Narrow-Band Imaging System to Chromoendoscopy With Indigo Carmine in Patients With Lynch Syndrome. Am. J. Gastroenterol. 2019, 114, 1665-1670, doi:10.14309/ajg.0000000000000386.

86. Rees, C.J.; Thomas-Gibson, S.; Rutter, M.D.; Baragwanath, P.; Pullan, R.; Feeney, M.; Haslam, N. UK key performance indicators and quality assurance standards for colonoscopy. Gut 2016, 65, 1923-1929, doi:10.1136/gutjnl-2016-312044.

87. Boonstra, J.J.; Cappel, W.H.D.V.T.N.; Langers, A.M.J.; Van Der Sluis, H.; Hardwick, J.H.; Vasen, H.F.A. Colonoscopy in Lynch syndrome: The need for a new quality score. Fam. Cancer 2016, 16, 239-241, doi:10.1007/s10689-016-9950-0.

88. Canto, M.I.; Harinck, F.; Hruban, R.H.; Offerhaus, G.J.; Poley, J.-W.; Kamel, I.; Nio, Y.; Schulick, R.S.; Bassi, C.; Kluijt, I.; et al. International Cancer of the Pancreas Screening (CAPS) Consortium summit on the management of patients with increased risk for familial pancreatic cancer. Gut 2012, 62, 339-347, doi:10.1136/gutjnl-2012-303108.

89. Neuzillet, C.; Gaujoux, S.; Williet, N.; Bachet, J.-B.; Bauguion, L.; Durand, L.C.; Conroy, T.; Dahan, L.; Gilabert, M.; Huguet, F.; et al. Pancreatic cancer: French clinical practice guidelines for diagnosis, treatment and follow-up (SNFGE, FFCD, GERCOR, UNICANCER, SFCD, SFED, SFRO, ACHBT, AFC). Dig. Liver Dis. 2018, 50, 1257-1271, doi:10.1016/j.dld.2018.08.008.

90. Canto, M.I.; Kerdsirichairat, T.; Yeo, C.J.; Hruban, R.H.; Shin, E.J.; Almario, J.A.; Blackford, A.; Ford, M.; Klein, A.P.; Javed, A.A.; et al. Surgical Outcomes After Pancreatic Resection of Screening-Detected Lesions in Individuals at High Risk for Developing Pancreatic Cancer. J. Gastrointest. Surg. 2019, 24, 1101-1110, doi:10.1007/s11605-019-04230-z.

91. Overbeek, K.; Levink, I.J.M.; Koopmann, B.D.M.; Harinck, F.; Konings, I.C.A.W.; Ausems, M.G.E.M.; Wagner, A.; Fockens, P.; van Eijck, C.H.; Koerkamp, B.G.; et al. Long-term yield of pancreatic cancer surveillance in high-risk individuals. Gut 2021, 5 avr2021, doi:10.1136/gutjnl-2020-323611.

92. Nishizawa, T.; Yahagi, N. Endoscopic mucosal resection and endoscopic submucosal dissection: Technique and new directions. Curr. Opin. Gastroenterol. 2017, 33, 315-319.

93. Lupu, A.; Jacques, J.; Rivory, J.; Rostain, F.; Pontette, F.; Ponchon, T.; Pioche, M. Endoscopic submucosal dissection with triangulated traction with clip and rubber band: The "wallet" strategy. Endoscopy 2018, 50, E256-E258.

94. Yamasaki, Y.; Takeuchi, Y.; Uedo, N.; Kanesaka, T.; Kato, M.; Hamada, K.; Tonai, Y.; Matsuura, N.; Akasaka, T.; Hanaoka, N.; et al. Efficacy of traction-assisted colorectal endoscopic submucosal dissection using a clip-and-thread technique: A prospective randomized study. Dig. Endosc. 2018, 30, 467-476, doi:10.1111/den.13036.

95. Langers, A.M.J.; Boonstra, J.J.; Hardwick, J.C.H.; van der Kraan, J.; Farina Sarasqueta, A.; Vasen, H.F.A. Endoscopic full thickness resection for early colon cancer in Lynch syndrome. Fam. Cancer 2019, 18, 349-352.

96. Aktan-Collan, K.; Kääriäinen, H.; Järvinen, H.; Peltomäki, P.; Pylvänäinen, K.; Mecklin, J.-P.; Haukkala, A. Psychosocial consequences of predictive genetic testing for Lynch syndrome and associations to surveillance behaviour in a 7-year follow-up study. Fam. Cancer 2013, 12, 639-646.

97. Esplen, M.J.; Wong, J.; Aronson, M.; Butler, K.; Rothenmund, H.; Semotiuk, K.; Madlensky, L.; Way, C.; Dicks, E.; Green, J.; et al. Long-term psychosocial and behavioral adjustment in individuals receiving genetic test results in Lynch syndrome. Clin. Genet. 2015, 87, 525-532.

98. Tarr, G.; Crowley, A.; John, R.; Kok, J.B.; Lee, H.-N.L.; Mustafa, H.; Sii, K.M.; Smith, R.; Son, S.-E.Q.; Weaver, L.J.; et al. Do high risk patients alter their lifestyle to reduce risk of colorectal cancer? BMC Gastroenterol. 2014, 14, 22, doi:10.1186/1471-230X-14-22.

99. Anderson, A.S.; Dunlop, J.; Gallant, S.; Macleod, M.; Miedzybrodzka, Z.; Mutrie, N.; E. O'Carroll, R.; Stead, M.; Steele, R.J.; Taylor, R.S.; et al. Feasibility study to assess the impact of a lifestyle intervention ('Living WELL') in people having an assessment of their family history of colorectal or breast cancer. BMJ Open 2018, 8, e019410, doi:10.1136/bmjopen-2017-019410.

100. Prichard, I.; Lee, A.; Hutchinson, A.D.; Wilson, C. Familial risk for lifestyle-related chronic diseases: Can family health history be used as a motivational tool to promote health behaviour in young adults? HealthPromot. J. Aust. 2015, 26, $122-128$.

101. Botma, A.; Nagengast, F.M.; Braem, M.G.; Hendriks, J.C.M.; Kleibeuker, J.H.; Vasen, H.F.; Kampman, E. Body Mass Index Increases Risk of Colorectal Adenomas in Men With Lynch Syndrome: The GEOLynch Cohort Study. J. Clin. Oncol. 2010, 28, 4346-4353, doi:10.1200/jco.2010.28.0453.

102. Watson, P.; Ashwathnarayan, R.; Lynch, H.T.; Roy, H.K. Tobacco use and increased colorectal cancer risk in patients with hereditary nonpolyposis colorectal cancer (Lynch syndrome). Arch. Intern. Med. 2004, 164, 2429-2431.

103. Dilzell, K.; Kingham, K.; Ormond, K.; Ladabaum, U. Evaluating the utilization of educational materials in communicating about Lynch syndrome to at-risk relatives. Fam. Cancer 2014, 13, 381-389, doi:10.1007/s10689-014-9720-9.

104. Corines, M.J.; Hamilton, J.; Glogowski, E.; Anrig, C.A.; Goldberg, R.; Niehaus, K.; Salo-Mullen, E.; Harlan, M.; Sheehan, M.R.; Trottier, M.; et al. Educational and Psychosocial Support Needs in Lynch Syndrome: Implementation and Assessment of an Educational Workshop and Support Group. J. Genet. Couns. 2017, 26, 232-243, doi:10.1007/s10897-016-0015-1. 